\title{
Evaluation of clinical effectiveness of Aloe vera - a review
}

\author{
Martyna Zagórska-Dziok', Dominika Furman-Toczek', Monika Dudra-Jastrzębska², Karol Zygo ${ }^{3}$, \\ Andrzej Stanisławek4, Lucyna Kapka-Skrzypczak ${ }^{1,5}$ \\ ${ }^{1}$ Chair of Medical Biology and Translational Research, Faculty of Medicine, University of Information Technology and \\ Management, Rzeszow, Poland \\ ${ }^{2}$ Department of Pathophysiology, Medical University of Lublin, Lublin, Poland \\ ${ }^{3}$ Department of Ethics and Human Philosophy, Medical University of Lublin, Lublin, Poland \\ ${ }^{4}$ Chair of Oncology and Environmental Health Care, Medical University of Lublin, Lublin, Poland \\ ${ }^{5}$ Department of Molecular Biology and Translational Research, Institute of Rural Health, Lublin, Poland
}

Zagórska-Dziok M, Furman-Toczek D, Dudra-Jastrzębska M, Zygo K, Stanisławek A, Kapka-Skrzypczak L. Evaluation of clinical effectiveness of Aloe vera - a review. J Pre-Clin Clin Res. 2017; 11(1): 86-93. doi: 10.26444/jpccr/74577

\section{Abstract}

Naturally occurring products have gained popularity in recent decades, especially due to their less adverse effects on human health. Various Aloe species are widespread all over the world. Aloe vera is one of the plants exhibiting multiple benefits and has gained considerable importance in clinical research. Historically, it has been used for a variety of medicinal purposes. It has attracted the attention of many researchers because of its different properties. More than 200 different biologically active substances were found in this plant that contributed to the fact it has been used to treat various types of diseases. The healthy effect of Aloe vera is primarily attributed to the polysaccharides contained in the gel of the leaves. It has been traditionally used to treat various conditions, including psoriasis, sunburn or radiation-related dermatitis, mucositis, oesophagitis or lichen planus. Aloe vera has also found application in wound healing, treatment of burns, protection against skin damage caused by X-ray, intestinal problems, reduction of plaque and gingivitis, regulating the levels of plasma lipoproteins, reduction of blood sugar levels and improving the immune system. Other biological activities of aloe, such as antifungal, antibacterial, antiviral, anti-inflammatory, anticancer and immunomodulatory have also been documented in numerous studies. This review examines the possible applications of Aloe vera in clinical trials.

\section{Key words}

Aloe vera, wound healing, periodontal health, antidiabetic activity

\section{INTRODUCTION}

Aloe vera is a cactus-like plant species belonging to the family Liliaceae [1]. Most cosmetic and medicinal products are produced from Aloe vera gel obtained from the mucilaginous tissue in the centre of the plant's leaves [2]. Aloe vera gel has been used since the Roman era or even earlier for many indications [3]. Its applications have been reported in the ancient cultures of Egypt, India, Greece, Rome and China [4]. Nowadays, substances derived from Aloe vera are components of many healthcare and cosmetic products widely available on the market. Aloe vera gel is also sold as a therapeutic agent in various concentrated, diluted and otherwise modified products. Almost 75 active ingredients have been identified in this gel, including vitamins, minerals, sugars, enzymes, lignin, saponins, anthraquinones or phenolic compounds, sterols, amino acids and salicylic acid (Fig. 1) [5,6].

Wound healing. A wound is an injury in the soft tissue of the skin surface caused by physical, chemical, electrical or thermal traumas. An inappropriate healing process can lead the wound to enter a chronic state which increases the risk of infection. Advanced mechanisms occurring in several phases are responsible for proper wound healing in humans. These

Address for correspondence: Martyna Zagórska-Dziok, Chair of Medical Biology and Translational Research, Faculty of Medicine, University of Information Technology and Management, Rzeszow, Poland

E-mail: mzagorska@wsiz.rzeszow.pl

Received: 31 May 2017; accepted: 8 June 2017 phases include thrombosis, inflammation, proliferation, healing and tissue reconstruction [7]. The most popular method for treating burn wounds is the administration of drugs to prevent penetration of infectious pathogens into the wound. Improvement in methods of wound healing and tissue recovery may enhance the quality of life of patients. It mayalso contribute to reduction of the costs of treatment [8]. Due to the fact that the treatment options for chronic wounds are still very limited, significant efforts have been made in the research into traditional therapies as alternative clinical wounds treatment.

Several different mechanisms have been proposed for the wound-healing effects of the extract from A.vera leaves. These include keeping the wound moist, faster maturation of collagen, increase in epithelial cell migration and reduction of inflammation [9]. The healing property of Aloe vera is related to compounds such as glucomannan and acemannan. The first of these is enriched in polysaccharides like mannose6-phosphate. The glucomannan up-regulates the fibroblast growth factor stimulating the proliferation of fibroblasts and improves collagen production. Acemannan increases periodontal ligament cell proliferation by up-regulating the growth factor 5, enhances type I collagen and alkaline phosphatase activity in primary human periodontal ligament cells [10].

To-date, a lot of research has been conducted on Aloe vera gel as a wound healer. Molazem et al. conducted randomized double-blind clinical trials on 90 women who had undergone cesarean operation. The patients were randomly divided into 


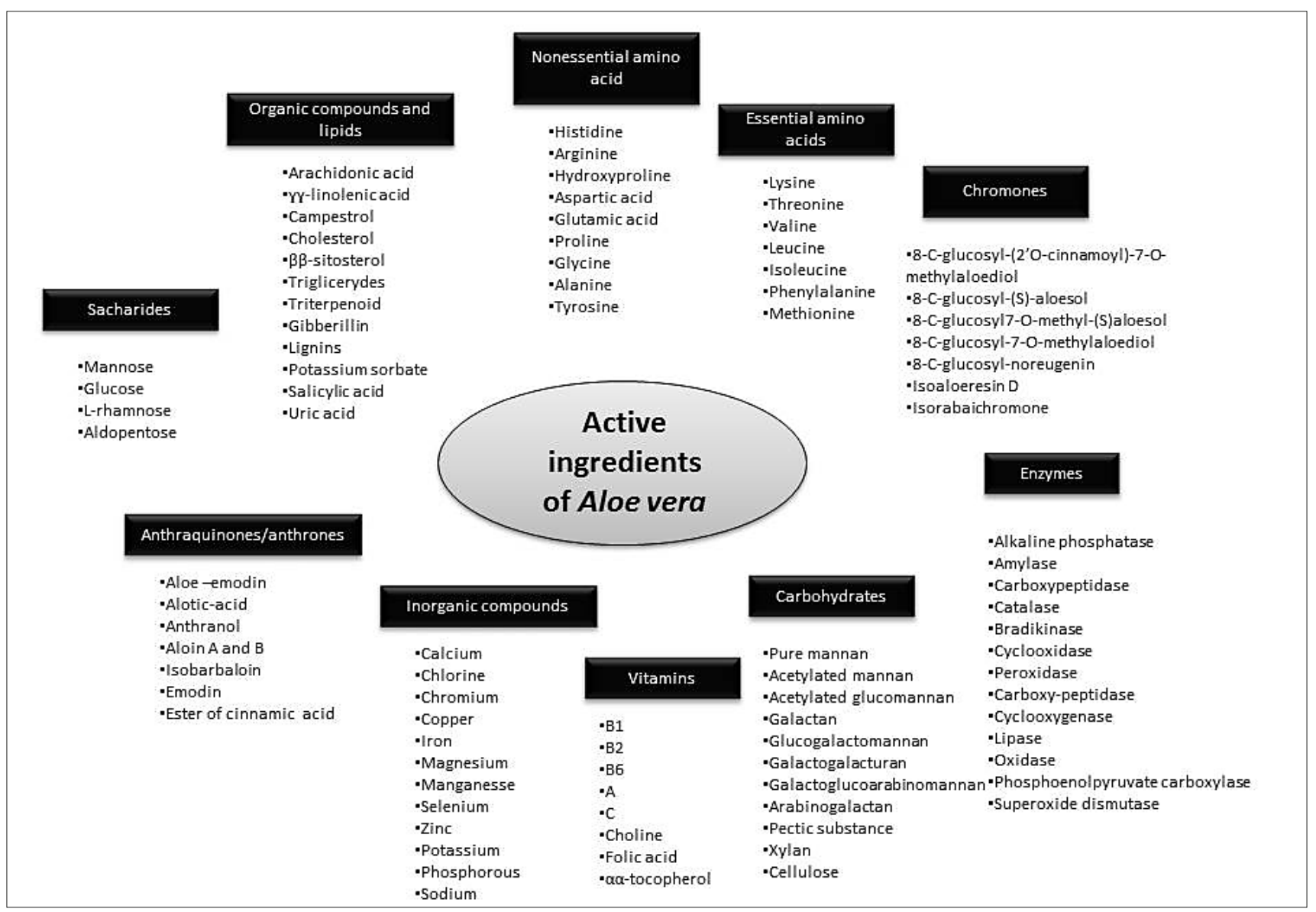

Figure 1. Active ingredients of Aloe vera $[5,6]$

two groups. Wounds of the participants in the first group were dressed with Aloe vera gel, while a simple dressing was used in the second group. Fresh, natural gel was used in order to preserve its effective substances, and incated that Aloe vera gel was effective in cesarean wound healing 24 hours post operation. The results revealed a significant difference between the Aloe vera and control groups. They also showed that dermal application of Aloe vera gel did not have any sideeffects; therefore, it could be used as an adjunctive treatment to the standard treatments of cesarean wounds [11].

Skin and mucosal disorders. Paulsen et al. conducted a randomized, double-blind, placebo-controlled study on 41 patients with stable plaque psoriasis. The study comprised a 2-week wash-out period followed bya 4-week treatment period with two applications daily, and follow-up visits after 1 and 2 months. Results of the study showed that the score sum of erythema, infiltration and desquamation decreased in the Aloe vera extract-treated sites, compared with the placebo-treated areas. No serious side-effects were recorded. However, 55\% of the patients reported local side-effects, mainly drying-up of the skin on test areas. The efficacy of treatment with Aloe vera gel was lower than treatment with placebo gel - a substance that only differed from the Aloe vera gel by the absence of the biologically active constituents [12].

Nappy rash and nappy dermatitis are common types of inflammatory disorders among infants and children who wear nappiess. Panahi et al. conducted randomized, double-blind trials on 32 infants in order to identify effective strategies to decrease the symptoms of nappy dermatitis in infants. Patients were treated with Aloe vera cream 3 times a day for 10 days. By the end of trial, severity of the nappy dermatitis was clearly decreased in infants treated with Aloe vera. Improvement of rash from baseline was also observed. There was no adverse effects from the study drug. Consequently, the results of these experiments show that topical application of Aloe vera gel can be used as a safe and well-functioning nappy dermatitis therapy [13]. These beneficial effects could be attributed to the well-known antiinflammatory properties of Aloe vera [14].

Vulval lichen planus is a chronic inflammatory disease of mucous membranes. It is quite common, affecting $1-2 \%$ of the population. Unfortunately, it is often resistant to treatment and its etiopathogenesis is still not very well known. Current treatments for this disorder are aimed at alleviating clinical symptoms, such as itching and inflammation [15]. Rajar et al. conducted a trial to compare the efficacy of Aloe vera gel in the topical management of this disorder. For this purpose, 34 female patients were randomized into 2 groups to receive Aloe vera gel or placebo for local application for 8 weeks. Thepatients suffered from erosive or ulcerative lesions and had vulval lichen planus, which was mainly located on the labia minora. Results of trial showed that the great majority of the patients treated with Aloe vera had a good response. Moreover, one patient treated with Aloe vera gel had complete clinical remission. No side-effects were observed in either group. The results of this study showed that Aloe vera gel might be a safe and effective treatment for reducing symptoms, or even inducing remission in vulval lichen planus [16]. 
Aloe sterols are plant sterols derived from Aloe vera. The results of Tanaka et al. in vivo experiments conducted on a mouse model showed that these compounds can regulate the metabolism of glucose [17]. The researchers also examined the influence of the intake of Aloe vera gel powder (AVGP) containing $40 \mu \mathrm{g}$ Aloe vera sterols on the skin conditions in Japanese women with dry skin. They conducted a randomized, double-blind, placebo-controlled trial on 54 Japanese women. All volunteers ingested 5 tablets per day (AVGP or placebo) for 8 weeks. The facial skin hydration levels were significantly increased in both groups. After 8 weeks, an increase in arm skin hydration was observed in the Aloe vera powder group, whereas a slight decrease in arm skin hydration was observed in the placebo group. It was also observed that the width and depth of the largest wrinkles decreased in the AVGP group. However, the differences in both groups were not significant. These experiments therefore showed that sterols contained in Aloe vera powder can reduce facial wrinkles in women [18].

An innovative dry-coating technology has produced a new concept, an examination glove that gradually delivers Aloe vera gel to the skin of the gloved hand. West et al. examined the effect of Aloe vera gel gloves in the treatment of dry skin associated with occupational exposure. They conducted a trial on 30 adult females with bilateral occupational dry skin, with or without irritant contact dermatitis. The females used the gloves for 8 hours a day on one hand, but not use on the other. The study was performed for 30 days, followed by 30 days rest, followed by 10 days of repeated use. Noticeable improvement in skin quality for the Aloe vera gloved hand was observed after 3.5 days (range: 2-6 days). The mean time to marked improvement in skin quality was 10.4 days (range: 7-17 days) for the tested glove hand. There was no improvement observed for non-glove hands in any of the women. No participants demonstrated any adverse reactions. Thus, the dry-coating of gloves with Aloe vera may improve skin integrity, decrease the appearance of fine wrinkling and decrease erythema [19].

Intrinsic aging and photo-aging of skin are induced by damage to human skin due to the passage of time or repeated exposure to ultraviolet (UV) irradiation from the sun. This irradiation has the ability to cause molecular responses that can damage skin connective tissue. The development of a novel compound that can delay the appearance of features of aging is desired [20]. Cho et al. conducted a clinical trial on 30 healthy female over the age of 45 . The participants received 2 different doses of Aloe vera gel - 1,200 mg/d and 3,600 mg/d for 90 days. Their baseline status was used as a control. At baseline and at the end of the study, facial wrinkles and facial elasticity was measured. Skin samples were taken before and after Aloe vera intake to compare the type I procollagen and matrix metalloproteinase $1 \mathrm{mRNA}$ levels. The study showed that Aloe vera significantly improved the facial wrinkles in both groups, and improved facial elasticity in the lower-dose group. In the photo-protected skin, the type I procollagen mRNA levels were increased in both groups. However, there was no statistically significant increase. The MMP-1 mRNA levels were significantly decreased in the higher-dose group. These results show that Aloe vera gel can significantly improve wrinkles and elasticity in photo-aged human skin. An increase in collagen production in the photo-protected skin and a decrease in the collagen-degrading MMP-1 gene expression was also noted [21].
Oral and periodontal health. Many plant products are widely used for the prevention and treatment of oral disorders. These chronic infectious diseases can lead to destruction of tooth supporting structures and ultimately to tooth loss. The 2 most common periodontal disorders are dental plaque-induced gingivitis and chronic periodontitis [22]. Advances in the treatment of various oral diseases are related to the use of various herbal and natural agents.

Oral lichen planus (OLP) is a chronic inflammatory disease of mucosal surfaces. It is quite common, affecting approximately $0.5 \%$ to $2 \%$ of the general population $[23,24]$. Choonhakarn et al. showed that Aloe vera can be successfully used in the treatment of this disorder. They conducted a randomized, doubled-blind, placebo-controlled trial on 54 patients (34 females and 20 males). Erosive and ulcerative lesions were found in $83 \%$ of women and in $17 \%$ of men. Participants were divided into 2 groups who received either Aloe vera gel or placebo for 8 weeks. $81 \%$ of patients treated with Aloe vera gel had a good response after 8 weeks of oral lichen planus treatment. By contrast, in the placebo group, only $4 \%$ had a similar response. Moreover, $7 \%$ of patients treated with Aloe vera gel had complete remission of symptomatology. Differences were also observed in the disappearance of burning pain. It disappeared completely in $8 \%$ of patients treated with Aloe vera gel and in $4 \%$ treated with placebo. A good response (symptomatology) was observed in improved by at least $50 \%$ in $63 \%$ of participants treated with Aloe vera, and in $7 \%$ treated with placebo. No serious side-effects were observed in either group. Aloe vera resulted in a decrease both in clinical signs and in pain scores. These trials showed that extract from Aloe vera is more effective in application to oral lichen planus than placebo, and can be a safe and promising alternative treatment for patients with this disorder [25].

Salazar-Sánchez et al. conducted a similar double-blind study to evaluate the efficacy of the topical application of Aloe vera in treatment of this disorder. They conducted trial on 64 patients with OLP. After 6 and 12 weeks of receiving $0.4 \mathrm{ml}$ aqueous suspension of Aloe vera or placebo, no statistically significant differences were recorded between both groups in relation to pain. In the Aloe vera group, complete pain remission was achieved in $31.2 \%$ of the cases after 6 weeks, and in $61 \%$ after 12 weeks. In the placebo group these percentages were $17.2 \%$ and $41.6 \%$, respectively. No side-effects effects were observed in any of the groups. Significant differences were observed between the 2 groups in relation to quality of life. These results showed that the topical application of Aloe vera may improve the quality of life in patients with OLP [26].

Recurrent aphthous stomatitis is one of the most common oral cavity lesions. It causes not only pain but could also a decrease the quality of life. Many chemical drugs have been shown to partially effective in alleviating patients' symptoms [27]. Babaee et al. conducted a double-blind clinical trial on 40 patients with oral minor aphthous lesions. The aim of their study was to evaluate topically-administered Aloe vera gel on oral cavity minor aphthous healing. Patients were randomly allocated to the Aloe vera gel group or the control (placebo) group. The authors recorded the lesion and its surrounding inflammation diameters at days $0,3,7$ and 10. Patients were trained to record their orange juicestimulated pain score every day for 10 days. The results showed that the healing times for pain and lesions in the 
Aloe vera treated group were significantly lower than in the control group. Furthermore, the pain severity was lower in the Aloe vera treated patients after 4 days, compared with the control group. After 3 and 7 days of administration, the circumscribed inflammation zone and lesion diameters in the Aloe vera treated group became significantly smaller than in the control group. Taking these results into consideration, it can be considered that it has a positive effect due to the decrease in healing time to less than 7 days [28].

Vangipuram et al. conducted a randomized, controlled trial on 390 dental students to assess the efficacy of Aloe vera mouthwash in preventing plaque accumulation and gingival inflammation. The Aloe vera group used $10 \mathrm{ml}$ of Aloe vera juice twice a day for 30 days. The placebo group used distilled water as mouthwash. A progressive reduction in both plaque and gingival index values was observed in the Aloe vera group. Based on these studies, it can be stated that Aloe vera can be used as an alternative product for curing and preventing gingivitis [29].

The effect of Aloe vera on the reduction of plaque and gingivitis was also evaluated by Oliveira et al. They conducted a randomized, parallel and double-blind clinical trial on 30 participants. The test group used a herbal dentifrice containing Aloe vera, and the control group used a fluoridated dentifrice with no anti-inflammatory properties. The participants were examined for plaque and gingivitis at baseline and after 30 days. Unfortunately, even after 30 days, plaque and gingival bleeding were present in both groups. The test dentifrice had a good acceptance and did not show any side-effects. The results of this study showed that the dentifrice containing Aloe vera did not show any additional effect, compared to the fluoridated dentifrice. It may be that the experimental period of 30 days was insufficient to show the superiority of the test dentifrice [30].

Chandrahas et al. conducted similar randomized, controlled and double-blind clinical trials on 120 patients. The subjects were requested to abstain from tooth brushing for 14 days and used a specially fabricated plaque guard. The participants were randomly divided into a test group who received $100 \%$ Aloe vera, a negative control group who received distilled water, and positive control group who received $0.2 \%$ chlorhexidine. The rinse regimen began on the day 15 and continued for 7 days. A statistically significant decrease wass observed in both plaque and gingival index values after the rinse regimen began in Aloe vera and positive control group, compared with the placebo group. Mouth wash containing Aloe vera showed a significant reduction of plaque and gingivitis, but in the case of the chlorhexidine mouthwash the effect was stronger. This study showed that the Aloe vera mouthwash can be used as an effective alternative antiplaque agent [31].

Oral submucous fibrosis is a disorder mainly associated with the chewing of areca nut. It is is a potentially malignant and crippling disease of the oral mucosa. It causes significant morbidity and mortality. The pathogenesis of this disorder is obscure and no definitive therapy is available [32]. Sudarshan et al. conducted a preliminary study on 20 patients with oral submucous fibrosis. They carried out this study to compare the efficacy of Aloe vera with antioxidants in the treatment of this disorder. Participants were divided into 2 groups. The first group received $5 \mathrm{mg}$ of Aloe vera gel and applied it topically 3 times daily for 3 months. The second group received antioxidant capsules twice daily for 3 months.
Patients who received Aloe vera gel demonstrated a better response in all the parameters assessed in all the clinical and histopathological stages, particularly in those with mild-stage clinically and early-stage histopathologically. Aloe vera showed a statistically significant reduction in burning sensation, improvement in mouth opening and cheek flexibility, compared to the antioxidant group. These results showed that Aloe vera gel can be a safe and effective agent in the treatment of oral submucous fibrosis [33].

Burning mouth syndrome is a chronic pain syndrome that mainly affects middle-aged or old women with hormonal changes or psychological disorders. It is manifested as a subjective burning sensation of the tongue, lips or entire oral cavity. This disorder does not manifest any objective lesions or laboratory test findings capable of accounting for the discomfort [34]. López-Jornet et al. conducted randomized, double-blind and placebo-controlled trial on 75 patients with burning mouth syndrome. The study was conducted to evaluate the efficacy of Aloe vera applied in combination with a tongue protector, comparing this with a placebo. The study was performed over a period of 12 weeks. The participants were randomized into 3 groups. The first group used the protector alone, the second group used the protector and Aloe vera, and the third group used the tongue protector and the placebo. This study showed that pain was reduced in the 3 study groups, but without statistically significant differences between the groups. Also, no significant differences were found in the quality of life between groups. The overall clinical improvement was greater for the group using Aloe vera, with a difference almost reaching significance. No patients experienced any side-effects resulting from the treatment at any of the evaluation times. Thus, the simultaneously use of a tongue protector and Aloe vera can be effective for treating patients with burning mouth syndrome [35].

Gastrointestinal diseases. Irritable bowel syndrome (IBS) is a common, multi-symptom gastrointestinal disorder. It affects approximately $9 \%-23 \%$ of the general population. The pathophysiology of this disorder is still uncertain. It is characterized by abdominal pain, change in bowel habit, feeling of incomplete evacuation and passage of mucus. There are many specific treatments available for this disorder [36]. Davis et al. conducted a double-blind, randomized placebocontrolled clinical trial to assess the efficacy of Aloe vera on irritable bowel syndrome in refractory secondary care patients. 58 patients with IBS were randomized to receive Aloe vera or placebo for a month. Symptoms were assessed at baseline and after 1 and 3 months of treatment. 35\% of Aloe vera patients and $22 \%$ of placebo patients responded at 1 month. At 3 months, there was continued improvement in the pain score in the Aloe vera group, but this was not significant. Thus, there was no overall benefit found among irritable bowel syndrome patients taking the Aloe vera treatment, compared to patients taking a matching placebo [37].

Langmead et al. conducted a double-blind, randomized, placebo-controlled trial of the efficacy and safety of Aloe vera gel for the treatment of mildly to moderately active ulcerative colitis. The trials were performed on 44 patients. Participants were randomized into 2 groups who received Aloe vera gel or placebo. They were randomly given both substances in a dose of $100 \mathrm{ml}$ twice daily for 4 weeks, in a 2:1 ratio. After 2 weeks of therapy, differences between patients taking Aloe vera and placebo did not reach statistical significance. After 4 
weeks of treatment, improvement and response of ulcerative colitis after Aloe vera gel administration appeared in $37 \%$ and $47 \%$, respectively. Complete clinical remission occurred in $30 \%$ of patients. In the placebo group, improvement occurred in $7 \%$, response in $14 \%$ and the clinical remission in $7 \%$ of patients. The results also showed reduction of histological disease activity and the safety of Aloe vera in the ulcerative colitis therapy. Adverse effect were minor and similar in both groups [38].

Radiation- and chemotherapy-induced disorders. Nowadays, two-thirds of patients diagnosed with cancer are treated with radiotherapy. Unfortunately, the majority of patients still experience adverse effects from treatment. The most common effect is acute dermatitis, occurring in about $95 \%$ of patients treated with this modality [39]. The prevention and treatment of radiation dermatitis is required for all radiation oncology patients. Many of the new compounds applied locally or systemically to prevent or treat radiationinduced mucositis have been investigated. Many authors have indicated that Aloe vera may provide an alternative agent for treating and minimalisation of radiation-induced reactions.

Haddad et al. evaluated an Aloe vera lotion for prevention of radiation-induced dermatitis. They conducted a selfcontrolled clinical trials on 60 patients. The radiation doses were in the range 40-70 Gy for a treatment duration of 26-49 days. Concurrent chemotherapy was administered in 20 patients. The mean grade of dermatitis was smaller in the Aloe vera group, compared to the control group. No significant difference between the halves of the irradiated area was observed in the participants until the end of the third week of radiotherapy. After 5 weeks of radiotherapy, $92 \%$ and $82 \%$ of the patients had at least grade 1 dermatitis on the untreated and Aloe vera treated side, respectively. No complications were caused by Aloe vera during the trial. This demonstrated the protective effect of Aloe vera lotion against radiation-induced dermatitis. The effect was more evident in patients undergoing radiotherapy with larger treatment fields and higher doses of radiation [40].

Puataweepong et al. conducted a double-blind, placebocontrolled trial to evaluate the efficacy of Aloe vera juice in the alleviation of radiation-induced mucositis. 61 eligible head and neck cancer patients after conventional radiation therapy were randomized to receive oral Aloe vera juice or placebo. The participants were asked to take $15 \mathrm{ml}$ of Aloe vera solution 3 times a day for 8 weeks. Mucosal reaction was assessed during the course of radiation. The incidence of severe mucositis was significantly lower in the Aloe vera group, compared to the placebo group (53\% vs. 87\%). This was statistically significant. However, there was no significant difference in the time-duration to severe mucositis development. The participants in the Aloe vera group had a lower percentage of weight loss and radiation breaks due to mucositis than patients in the placebo group, but the difference was not statistically significant. No adverse effects related to the drug were observed. These results showed that oral Aloe vera juice had benefits in alleviating the severity of radiation-induced mucositis, and should be considered as a good alternative agent for treating radiation-induced mucositis in patients with head and neck cancers [41].

Unfortunately, many clinical trials have not provided promising results. Merchant et al. compared an anionic polar phospholipid (APP)-based cream and an Aloe vera-based gel to determine their effectiveness in preventing and treating radiation dermatitis. Clinical trials were conducted on 45 pediatric patients with various diagnoses. All participants received at least $23.4 \mathrm{~Gy}$. APP cream and Aloe vera gel which were symmetrically applied within the irradiated field after each treatment. Unfortunately, the results of these studies showed that the anionic phospholipid-based cream was significantly more effective than Aloe vera gel in the prevention and treatment of radiation-induced dermatitis [42].

The study conducted by Heggie et al. also did not confirm the unusual properties of Aloe vera gel in reducing dry desquamation and treatment-related pain. They conducted trials on 225 breast-cancer patients undergoing radiation therapy after lumpectomy or partial mastectomy. Participants received $98 \%$ Aloe vera gel or aqueous cream. These compounds were applied 3 times daily by the patient to the irradiated area. This procedure was performed throughout the treatment period and for 2 weeks after radiation therapy. The aqueous group experienced a greater but non-significant incidence of erythema, compared with the group treated with Aloe vera gel. Moreover, patients who had undergone axillary surgery experienced more pain, erythema and itching if they were in the Aloe vera group. However, in the case of the non-chemotherapy patients, the Aloe vera participants experienced a significantly reduced incidence of moderate or more erythema, compared with participants treated with aqueous cream. The results of these trials showed that Aloe vera gel is worse than aqueous cream in treating radiationinduced reactions [43].

Chemotherapy is one of the most common cancer treatments. It is the first line therapy for leukemia and lymphomas. Unfortunately, application of this method of treatment is associated with numerous side-effects [44] which require medical and nursing interventions. Mansouri et al. evaluated the effectiveness of Aloe vera in the intensity of stomatitis and its pain. For this purpose, they conduct randomized, controlled clinical trials on 64 patients with acute myeloid leukemia and acute lymphocytic leukemia undergoing chemotherapy. The participants were randomly divided into a control and an Aloe vera mouthwash group. They were asked to wash their mouths with $5 \mathrm{ml}$ of Aloe vera solution 3 times a day for 14 days. The control group used ordinary mouthwashes recommended in haematologic centers. The results showed that the Aloe vera solution mouthwash significantly reduced the intensity of stomatitis and its pain in the intervention group, compared to the control group. A significant difference was found regarding the intensity of stomatitis and pain on days 3-14. The results of this clinical trial showed that Aloe vera solution was effective in decreasing stomatitis intensity and pain. For this, Aloe vera can be useful in preventing and treating stomatitis in patients with chemotherapy-induced stomatitis without any adverse effects [45].

Antidiabetic activity. The number of people with diabetes is increasing mainly due to population growth, aging and increasing prevalence of obesity and physical inactivity. Diabetes mellitus is a group of metabolic disorders that is one of the major global health threats to humans due to its disabling complications and chronic course [46]. Nowadays, several medical plants, such as Aloe vera, are gaining increasing popularity among patients with hyperglycemia, due to affordability and fewer adverse effects. 
Yongchaiyudha et al. investigated the effect of oral administration of Aloe vera juice in patients with diabetes. They conducted clinical trial on 77 participants divided equally for treatment into an Aloe vera group and a control group. The results showed that the blood sugar levels of patients who received Aloe vera juice were significantly reduced after one week, and continued to fall steadily throughout the treatment period. This parameter did not change in the control group. The triglyceride levels in the Aloe vera group were significantly reduced after 2 weeks of treatment and fell further by the end of the study. The level of cholesterol was not affected by administration of Aloe vera in patients with diabetes. This study suggests that Aloe vera possesses potential antidiabetic activity [47].

Yagi et al. conducted a clinical trial on 15 patients with type 2 diabetes mellitus to investigate the efficacy of Aloe vera high molecular weight fractions (AHM) prepared by the patented hyper-dry technique in the treatment of this metabolic disorder. All the participants received 2 tablespoonful of AHM 3 times daily for 12 weeks while continuing to take their hypoglycemic medications. This trial showed that the treatment of patients with AHM for 12 weeks with their oral hypoglycaemic agents resulted in a significant decrease in fasting blood glucose by $32 \%$, compared to before administration. This decrease was significant and sustained after 6 weeks from the start of the study. The triglycerides level was also decreased significantly. Treatment of the patients with Aloe vera high molecular weight fractions with the oral hypoglycaemic agents did not result in any change in cholesterol levels, compared to before the treatment. Glycosylated haemoglobin values showed a significant reduction by $20 \%$, compared to before treatment. Treatment of the patients with AHM did not result in any change in serum activities of serum aspartate aminotransferase, serum alanine aminotransferase and serum creatinine. This study showed that Aloe vera high molecular weight fractions exhibited a significant hypoglycaemic effect. It can lower not only the glucose level but also the triglycerides level which are often high in diabetic patients [48].

Antibacterial activity. Dental caries is a common chronic disease. It is related to the interaction between oral flora, teeth, and diet. Microorganisms play a important role in the causation of dental caries. Bacteria such as Streptococcus mutans or Lactobacillus colonizing the oral cavity are considered to be associated with the initiation of dental caries [49]. Complete removal of microorganisms from the oral cavity is impossible, but their count can be reduced by using various oral hygiene measures.

Bhati et al. comparatively evaluated the antimicrobial efficacy of fluoridated and Aloe vera dentifrices. They conduct a trial on 60 students in the 6-12 years age group. Participants were divided into groups by utilizing a simple random sampling method. The authors compared the number of bacteria in patients using a fluoride-containing dentifrice, an Aloe vera containing dentifrice, and in patients who did not use any dentifrice. Salivary samples were collected at the washout period of 2 days, 15 days, and 30 days, and cultured on agar for determining Streptococcus mutans count. These Streptococcusmutans colonies on the plate were expressed as the number of colony-forming units per millilitre (CFU/ $\mathrm{ml}$ ) of saliva. The study took place over a period of one month. In all the groups, the mean percentage value of CFU/ $\mathrm{ml}$ increased after a washout period of 2 days. After this washout period, a continuous reduction in microbial count was observed in the fluoridated dentifrice group and Aloe vera dentifrice group. The mean percentage of CFU $/ \mathrm{ml}$ count of the Aloe vera group showed a reduction by $80.95 \%$. In the group where no dentifrice was used, a constant increase in $\mathrm{CFU} / \mathrm{ml}$ count was observed which increased by $55.93 \%$ after the washout period. This study showed that herbal dentifrices containing Aloe vera can be safely recommended as an alternative to fluoridated dentifrices in terms of antimicrobial efficacy [50].

A similar trial was also conducted by Prabhakar et al. They evaluated the efficacy of hand instruments in excavating dental caries and the role of Aloe vera as potential cavity disinfecting agent. The study included a control group and an Aloe vera group. Dentinal samples were collected 3 times from each carious tooth and subjected to microbiological analyses for total viable count. A statistically significant reduction in the bacterial count was observed in both groups post-excavation and post-cavity disinfection. In the Aloe vera group, a significant reduction in the number of bacterial colonies, compared to control group, was observed. The results of this trial showed that Aloe vera extract can be used as a potential, natural disinfecting agent [51].

\section{CONCLUSIONS}

Aloe vera is a very important plant, especially because of its large number of medicinal properties. The pharmacological properties of this plant have been evaluated in several clinical trials (Tab. 1). These effects include the potential of whole leaf or inner gel liquid preparations. Aloe vera gel, which is widely used in the food, health care and medicinal industries, is extracted from Aloe vera leaves and then specially processed into the final product. It is also important to enhance the intestinal absorption and bioavailability of administered compounds. Aloe vera is one of the plants with a very long history of healing of skin wounds and burns. Clinical studies show its extremely useful in the treatment of various types of wounds. Results of these trials demonstrates that Aloe vera might be effective in improving the wound healing process and increasing the rate of effective treatment. Researchers have also conducted studies on the potential use of Aloe vera in the treatment of various skin and mucous membranes diseases. The results of these trials showed that Aloe vera can be used effectively in the treatment of a variety of disorders, such as psoriasis, nappy dermatitis and vulval lichen planus. It also has a positive effect on dry skin condition and showed a marked improvement in skin quality. Research also indicates that Aloe vera can be used with great effectiveness for treating various oral and dental diseases. Trials showed that Aloe vera gel is effective in inducing the clinical and symptomatological improvement of oral lichen planus, and can be considered a safe alternative treatment for patients with this disorder. It is also partially effective in alleviating symptoms in patients with aphthous stomatitis. Other authors have conducted a study to assess efficacy of Aloe vera in preventing plaque accumulation and gingival inflammation. They proved that it results in a reduction in both plaque and gingival index values. Aloe vera is also an effective agent in the treatment of oral submucous fibrosis and burning mouth syndrome. Clinical trials showed a reduction in histological disease 
Table 1. Clinical effectiveness of Aloe vera

\begin{tabular}{|c|c|c|}
\hline Disease & Action of Aloe vera & References \\
\hline \multicolumn{3}{|c|}{ WOUND HEALING } \\
\hline $\begin{array}{l}\text { Cesearean and } \\
\text { burn wounds }\end{array}$ & $\begin{array}{l}\text { keeps wound moist } \\
\text { causes faster maturation of collagen } \\
\text { increases epithelial cell migration } \\
\text { reduces inflammation } \\
\text { upregulates fibroblast growth factor } \\
\text { stimulates cell proliferation } \\
\text { improves collagen production and secretion } \\
\text { improves periodontal ligament cell proliferation } \\
\text { upregulates growth factor } 5 \\
\text { enhances type I collagen and alkaline phosphatase } \\
\text { activity } \\
\text { is effective in cesarean wound healing } \\
\text { does not cause any side-effects }\end{array}$ & $\begin{array}{l}{[9]} \\
{[10]} \\
{[11]}\end{array}$ \\
\hline \multicolumn{3}{|c|}{ SKIN AND MUCOSAL DISORDERS } \\
\hline $\begin{array}{l}\text { Plaque } \\
\text { psoriasis }\end{array}$ & $\begin{array}{l}\text { reduces score sum of erythema, infiltration and } \\
\text { desquamation } \\
\text { causes only local side-effects }\end{array}$ & [12] \\
\hline $\begin{array}{l}\text { Nappy } \\
\text { dermatitis }\end{array}$ & $\begin{array}{l}\text { decreases severity of nappy dermatitis } \\
\text { reduces rash } \\
\text { does not cause any adverse effect }\end{array}$ & [13] \\
\hline $\begin{array}{l}\text { Vulval lichen } \\
\text { planus }\end{array}$ & $\begin{array}{l}\text { results in a good response in patients with vulval } \\
\text { lichen planus located on labia minora } \\
\text { does not cause side-effects }\end{array}$ & [16] \\
\hline Dry skin & $\begin{array}{l}\text { increases facial skin hydration levels } \\
\text { increases arm skin hydration } \\
\text { reduces wrinkle depth } \\
\text { improves skin quality } \\
\text { does not cause any adverse reactions } \\
\text { improves skin integrity } \\
\text { decreases appearance of fine wrinkling } \\
\text { decreases erythema }\end{array}$ & $\begin{array}{l}{[18]} \\
{[19]}\end{array}$ \\
\hline $\begin{array}{l}\text { Intrinsic } \\
\text { aging and } \\
\text { photoaging } \\
\text { of skin }\end{array}$ & $\begin{array}{l}\text { improves facial wrinkles and facial elasticity } \\
\text { increases type I procollagen mRNA levels } \\
\text { decreases MMP-1 mRNA levels } \\
\text { improves wrinkles and elasticity in photoaged } \\
\text { human skin } \\
\text { increases collagen production in the } \\
\text { photoprotectedskin } \\
\text { decreases collagen- degrading MMP-1gene } \\
\text { expression }\end{array}$ & {$[21]$} \\
\hline \multicolumn{3}{|c|}{ ORAL AND PERIODONTAL HEALTH } \\
\hline $\begin{array}{l}\text { Oral lichen } \\
\text { planus }\end{array}$ & $\begin{array}{l}\text { decreases clinical signs and pain scores } \\
\text { causes remission in } 61 \% \text { after } 12 \text { weeks } \\
\text { improves quality of life } \\
\text { does not cause serious side-effects }\end{array}$ & $\begin{array}{l}{[25]} \\
{[26]}\end{array}$ \\
\hline $\begin{array}{l}\text { Aphthous } \\
\text { stomatitis }\end{array}$ & $\begin{array}{l}\text { reduces healing times for pain and lesions } \\
\text { reduces pain severity } \\
\text { decreases circumscribed inflammation zone and } \\
\text { lesion diameters }\end{array}$ & {$[28]$} \\
\hline
\end{tabular}

activity and the safety of Aloe vera in ulcerative colitis and irritable bowel syndrome therapy. Many authors indicate that Aloe vera may provide an alternative agent for the treatment and minimalisation of radiation-induced reactions. Although many studies have provided promising results in radiationinduced reactions treatment, some of them, however, denied the effectiveness of Aloe vera in prevention and treatment of radiation dermatitis. However, it is proven that Aloe vera can be useful in preventing and treating stomatitis in patients with chemotherapy-induced stomatitis without any adverse effects. Currently, available data shows that Aloe vera exhibits a significant hypoglycaemic effect, which is mainly associated with the reduction of blood glucose and triglycerides level in diabetics patients. Other results showed that Aloe vera extract

\begin{tabular}{|c|c|c|}
\hline Disease & Action of Aloe vera & References \\
\hline $\begin{array}{l}\text { Plaque } \\
\text { accumulation } \\
\text { and gingival } \\
\text { inflammation }\end{array}$ & $\begin{array}{l}\text { reduces plaque and gingival index values } \\
\text { does not cause any side-effects }\end{array}$ & $\begin{array}{l}{[29]} \\
{[30]} \\
{[31]}\end{array}$ \\
\hline $\begin{array}{l}\text { Oral } \\
\text { submucous } \\
\text { fibrosis }\end{array}$ & $\begin{array}{l}\text { causes good response in all the parameters } \\
\text { assessed in all the clinical and histopathological } \\
\text { stages } \\
\text { reduces burning sensation } \\
\text { improves mouth opening and cheek flexibility }\end{array}$ & [33] \\
\hline $\begin{array}{l}\text { Burning mouth } \\
\text { syndrome }\end{array}$ & $\begin{array}{l}\text { reduces pain } \\
\text { causes overall clinical improvement } \\
\text { does not cause any side effects }\end{array}$ & {$[35]$} \\
\hline \multicolumn{3}{|c|}{ GASTROINTESTINAL DISEASES } \\
\hline $\begin{array}{l}\text { Irritable bowel } \\
\text { syndrome }\end{array}$ & reduces pain & [37] \\
\hline $\begin{array}{l}\text { Active } \\
\text { ulcerative } \\
\text { colitis }\end{array}$ & $\begin{array}{l}\text { causes complete clinical remission in } 30 \% \text { of } \\
\text { patients } \\
\text { reduces histological disease activity } \\
\text { cause small adverse effect }\end{array}$ & {$[38]$} \\
\hline \multicolumn{3}{|c|}{ RADIATION- AND CHEMOTHERAPY-INDUCED DISORDERS } \\
\hline $\begin{array}{l}\text { Radiation- } \\
\text { induced } \\
\text { dermatitis }\end{array}$ & $\begin{array}{l}\text { causes protective effect } \\
\text { does not cause any complications }\end{array}$ & {$[40]$} \\
\hline $\begin{array}{l}\text { Radiation- } \\
\text { induced } \\
\text { mucositis }\end{array}$ & $\begin{array}{l}\text { reduces incidence of severe mucositis } \\
\text { causes lower percentage of weight loss and } \\
\text { radiation breaks } \\
\text { does not cause adverse effects } \\
\text { alleviates severity of radiation-induced mucositis } \\
\text { is less effective than anionic phospholipid-based } \\
\text { cream and aqueous cream in treating radiation- } \\
\text { induced reactions }\end{array}$ & $\begin{array}{l}{[41]} \\
{[42]} \\
{[43]}\end{array}$ \\
\hline $\begin{array}{l}\text { Chemotherapy- } \\
\text { induced } \\
\text { stomatitis }\end{array}$ & reduces intensity of stomatitis and its pain & {$[45]$} \\
\hline \multicolumn{3}{|c|}{ ANTIDIABETIC ACTIVITY } \\
\hline Diabetes & $\begin{array}{l}\text { reduces blood sugar levels and } \\
\text { reduces triglyceride levels } \\
\text { does not change cholesterol level } \\
\text { decreases glycosylated haemoglobin values } \\
\text { does not cause any change in serum activities of } \\
\text { serum aspartate aminotransferase, serum alanine } \\
\text { aminotransferase and serum creatinine. }\end{array}$ & $\begin{array}{l}{[47]} \\
{[48]}\end{array}$ \\
\hline \multicolumn{3}{|c|}{ ANTIBACTERIAL ACTIVITY } \\
\hline Dental caries & reduces number of bacterial colonies & $\begin{array}{l}{[50]} \\
{[51]}\end{array}$ \\
\hline
\end{tabular}

can be used as a natural disinfecting agent, and in alternative dentifrices in terms of antimicrobial efficacy.

The results of clinical research described in this study are undoubtedly promising; however, further well-designed clinical trials with sufficient details of the contents of Aloe vera products should be carried out for determining its effectiveness in the treatment of many diseases under various conditions.

\section{REFERENCES}

1. Grindlay D, Reynolds T. The Aloe vera phenomenon: a review of the properties and modern uses of the leaf parenchyma gel. J Ethnopharmacol. 1986; 16(2-3): 117-51. 
2.Little JW. Complementary and alternative medicine: impact on dentistry. Oral Surg Oral Med Oral Pathol Oral Radiol Endod. 2004; 98: $137-45$.

3. Morton JF. Folk uses and commercial exploitation of Aloe leaf pulp. Econ Bot. 1961; 15: 311-19.

4. Ahlawat KS, Khatkar BS. Processing, food applications and safety of Aloe vera products: a review. J Food Sci Technol. 2011; 48: 525-33

5. Hamman JH. Composition and applications of Aloe vera leaf gel. Molecules. 2008; 13: 1599-616.

6. Gupta VK, Malhotra S. Pharmacological attribute of Aloe vera: Revalidation through experimental and clinical studies. Ayu. 2012 33(2): 193-6.

7. Ghaderi R, Afshar M, Akhbarie H, Golalipour MJ. Comparison of the efficacy of honey and animal oil in accelerating healing of full thickness wound of mice skin. Int J Morphol. 2010; 28(1): 193-198.

8. Blanks T. Mind, Body, and Soul: Body Shop Book of Wellbeing. Ebury Press. London, 1998.

9. Reynolds T, Dweck AC. Aloe vera leaf gel: A review update. J Ethnopharmacol. 1999; 68: 3-37.

10. Boudreau MD, Beland FA. An evaluation of the biological and toxicological properties of Aloe barbadensis (miller), Aloe vera J Environ Sci Health C Environ Carcinog Ecotoxicol Rev. 2006; 24(1): $103-54$.

11. Molazem Z, Mohseni F, Younesi M, Keshavarzi S. Aloe veragel and cesarean wound healing; arandomized controlled clinical trial. Glob J Health Sci. 2014; 7(1): 203-9.

12. Paulsen E, Korsholm L, Brandrup F. A double-blind, placebo-controlled study of a commercial Aloe vera gel in the treatment of slight to moderate psoriasis vulgaris. J Eur Acad Dermatol Venereol. 2005; 19(3): 326-31.

13. Panahi Y, Sharif MR, Sharif A, Beiraghdar F, Zahiri Z, Amirchoopani $\mathrm{G}$, et al. A randomized comparative trial on the therapeutic efficacy of topical Aloe vera and Calendula officinalis on diaper dermatitis in children. Scientific World Journal. 2012; 2012: 810234

14. Reuter J, Jocher A, Stump J, Grossjohann B, Franke G, Schempp CM. Investigation of the anti-inflammatorypotential of Aloe vera gel (97.5\%) in the ultraviolet erythema test. Skin Pharmacol Physiol. 2008; 21(2): $106-110$.

15. Bhattacharya M, Kaur I, Kumar B. Lichen planus: a clinical and epidemiological study. J Dermatol. 2000; 27: 576-82.

16. Rajar UD, Majeed R, Parveen N, Sheikh I, Sushel C. Efficacy of Aloe veragel in the treatment of vulval lichen planus. J Coll Physicians Surg Pak. 2008; 18(10): 612-4.

17. Tanaka M, Misawa E, Ito Y, Habara N, Nomaquchi K, Yamada M, et al. Identification of five phytosterols from Aloe vera gel as anti-diabetic compounds. Biol Pharm Bull. 2006; 29(7): 1418-22.

18. Tanaka M, Misawa E, Yamauchi K, Abe F, Ishizaki C.Effects of plant sterols derived from Aloe vera gel on human dermal fibroblasts in vitro and on skin condition in Japanese women. Clin Cosmet Investig Dermatol. 2015; 8: 95-104.

19. West DP, Zhu YF. Evaluation of Aloe vera gel gloves in the treatment of dry skin associated with occupational exposure. Am J Infect Control. 2003; 31(1): 40-2.

20. Fisher GJ, Kang S, Varani J, Bata-Csorgo Z, Wan Y, Datta S, et al. Mechanisms of photoaging and chronological skin aging. Arch Dermatol. 2002; 138(11): 1462-70.

21. Cho S, Lee S, Lee MJ, Lee DH, Won CH, Kim SM, et al. Dietary Aloe Vera Supplementation Improves Facial Wrinkles and Elasticity and It Increases the Type I Procollagen Gene Expression in Human Skin in vivo. Ann Dermatol. 2009; 21(1): 6-11.

22. Tatakis DN, Kumar PS. Etiology and pathogenesis of periodontal diseases. Dent Clin North Am. 2005; 49(3): 491-516.

23. Gupta S, Jawanda MK. Oral Lichen Planus: An Update on Etiology, Pathogenesis, Clinical Presentation, Diagnosis and Management. Indian J Dermatol. 2015; 60(3): 222-229.

24. Sugerman PB, Savage NW, Zhou X, Walsh LJ, Bigby M. Oral lichen planus. Clin Dermatol. 2000; 18: 533-9.

25. Choonhakarn C, Busaracome P, Sripanidkulchai B, Sarakarn P. The efficacy of Aloe vera gel in the treatment of oral lichen planus: a randomized controlled trial. Br J Dermatol. 2008; 158(3): 573-7.

26. Salazar-Sánchez N, López-Jornet P, Camacho-Alonso F, Sánchez-Siles M. Efficacy of topical Aloe vera in patients with oral lichen planus: a randomized double-blind study. J Oral Pathol Med. 2010;39(10): 735-40.

27. Altenburg A, Zouboulis CC. Current concepts in the treatment of recurrent aphthous stomatitis. Skin Therapy Lett. 2008; 13(7): 1-4.

28. Babaee N, Zabihi E, Mohseni S, Moghadamnia AA. Evaluation of the therapeutic effects of Aloe vera gel on minor recurrent aphthous stomatitis. Dent Res J. 2012; 9(4): 381-5.
29. Vangipuram S, Jha A, Bhashyam M. Comparative efficacy of Aloe vera mouthwash and chlorhexidine on periodontal health: A randomized controlled trial. J Clin Exp Dent. 2016; 8(4): e442-e447.

30. de Oliveira SM, Torres TC, Pereira SL, Mota OM, Carlos MX. Effect of a dentifrice containing Aloe vera on plaque and gingivitis control. A double-blind clinical study in humans. J Appl Oral Sci. 2008; 16(4): 293-6.

31. Chandrahas B, Jayakumar A, Naveen A, Butchibabu K, Reddy PK, Muralikrishna T. A randomized, double-blind clinical study to assess the antiplaque and antigingivitis efficacy of Aloe vera mouth rinse. J Indian Soc Periodontol. 2012; 16(4): 543-8.

32. Warnakulasuriya S, Johnson NW, van der Waal I. Nomenclature and classification of potentially malignant disorders of the oral mucosa. J Oral Pathol Med. 2007; 36(10): 575-80.

33. Sudarshan R, Annigeri RG, SreeVijayabala G. Aloe vera in the treatment for oral submucous fibrosis - a preliminary study. J Oral Pathol Med. 2012; 41(10): 755-61.

34. Scala A, Checchi L, Montevecchi M, Marini I, Giamberardino MA. Update on burning mouth syndrome: overview and patient management. Crit Rev Oral Biol Med. 2003; 14(4): 275-91.

35. López-Jornet P, Camacho-Alonso F, Molino-Pagan D.Prospective, randomized, double-blind, clinical evaluation of Aloe veraBarbadensis, applied in combination with a tongue protect or to treat burning mouth syndrome. J Oral Pathol Med. 2013; 42(4): 295-301.

36. Saha L. Irritable bowel syndrome: Pathogenesis, diagnosis, treatment, and evidence-based medicine. World J Gastroenterol. 2014; 20(22): 6759-73.

37. Davis K, Philpott S, Kumar D, Mendall M. Randomised double-blind placebo-controlled trial of Aloe vera for irritable bowel syndrome. Int J Clin Pract. 2006; 60(9): 1080-6.

38. Langmead L, Feakins RM, Goldthorpe S, Holt H, Tsironi E, De Silva A, et al. Randomized, double-blind, placebo-controlled trial of oral Aloe vera gel for active ulcerative colitis. Aliment Pharmacol Ther. 2004; 19(7): 739-47.

39. Ryan JL. Ionizing radiation: the good, the bad, and the ugly. J Invest Dermatol. 2012; 132(3): 985-93.

40. Haddad P, Amouzgar-Hashemi F, Samsami S, Chinichian S, Oghabian MA. Aloe vera for prevention of radiation-induced dermatitis: a selfcontrolled clinical trial. Curr Oncol. 2013; 20(4): e345-8.

41. Puataweepong P, Dhanachai M, Dangprasert S, Sithatani C, Sawangsilp $\mathrm{T}$, NarkwongL, et al. The efficacy of oral Aloe vera juice for radiation induced mucositis in head and neck cancer patients: a double-blind placebo-controlled study. Asian Biomed. 2009; 3(4): 375-82.

42. Merchant TE, Bosley C, Smith J, Baratti P, Pritchard D, Davis T, et al. A phase III trial comparing an anionic phospholipid-basedcream and Aloe vera-based gel in the prevention and treatment of radiation dermatitis in pediatric pantients. Radiat Oncol. 2007; 2: 45.

43. Heggie S, Bryant GP, Tripcony L, Keller J, Rose P, Glendenning M, et al. A Phase III study on theefficacy of topical Aloe vera gel on irradiated breast tissue. Cancer Nurs. 2002; 25(6): 442-51.

44. Ramirez LY, Huestis AE, Yap TY, Zyzanski S, Drotar D, Kodish E. Potential Chemotherapy Side Effects. What Do Oncologists Tell Parents? Pediatr Blood Cancer. 2009; 52(4): 497-502.

45. Mansouri P, Haghighi M, Beheshtipour N, Ramzi M. The effect of Aloe vera solution on chemothetapy-induced stomatitis in clients with lymphoma and leukemia: a randomized controlled clinical trial. Int J Community Based Nurs Midwifery. 2016; 4(2): 119-26.

46. Wild S, Roglic G, Green A, Sicree R, King H. Global prevalence of diabetes: estimates for the year 2000 and projections for 2030. Diabetes Care. 2004; 27(5): 1047-53.

47. Yongchaiyudha S, Rungpitarangsi V, Bunyapraphatsara N, Chokechaijaroenporn O. Antidiabetic activity of Aloe vera L. juice. I. Clinical trial in newcases of diabetes mellitus. Phytomedicine. 1996; 3(3): 241-3.

48. Yagi A, Hegazy S, Kabbash A, Wahab EA. Possible hypoglycemic effect of Aloe vera L. high molecular weight fractions on type 2 diabetic patients. Saudi Pharm J. 2009; 17(3): 209-15.

49. Tanzer JM, Livingston J, Thompson AM. The microbiology of primary dental caries in humans. J Dent Educ. 2001; 65(10): 1028-37.

50. Bhati N, Jaidka S, Somani R. Evaluation of antimicrobial efficacy of Aloe vera and Meswak containing dentifrices with fluoridated dentifrice: An in vivo study. J Int Soc Prev Community Dent. 2015; 5(5): 394-9.

51. Prabhakkar AR, Karuna YM, Yavagal C, Deepak BM. Cavity disinfection in minimally invasive dentistry - comparative evaluation of Aloe vera and propolis: A randomized clinical trial. Contemp Clin Dent. 2015; 6(1): S24-31. 